\title{
Genome sequencing and comparison of five Tilletia species to identify candidate genes for the detection of regulated species infecting wheat
}

Hai D. T. Nguyen ${ }^{1 *}$, Tahera Sultana ${ }^{1,2}$, Prasad Kesanakurti ${ }^{1,3}$ and Sarah Hambleton ${ }^{1 *}$

\begin{abstract}
Tilletia species cause diseases on grass hosts with some causing bunt diseases on wheat (Triticum). Two of the four species infecting wheat have restricted distributions globally and are subject to quarantine regulations to prevent their spread to new areas. Tilletia indica causes Karnal bunt and is regulated by many countries while the nonregulated T. walkeri is morphologically similar and very closely related phylogenetically, but infects ryegrass (Lolium) and not wheat. Tilletia controversa causes dwarf bunt of wheat (DB) and is also regulated by some countries, while the closely related but non-regulated species, T. caries and T. laevis, both cause common bunt of wheat (CB). Historically, diagnostic methods have relied on cryptic morphology to differentiate these species in subsamples from grain shipments. Of the DNA-based methods published so far, most have focused on sequence variation among tested strains at a single gene locus. To facilitate the development of additional molecular assays for diagnostics, we generated whole genome data for multiple strains of the two regulated wheat pathogens and their closest relatives. Depending on the species, the genomes were assembled into 907 to 4633 scaffolds ranging from $24 \mathrm{Mb}$ to $30 \mathrm{Mb}$ with 7842 to 9952 gene models predicted. Phylogenomic analyses confirmed the placement of Tilletia in the Exobasidiomycetes and showed that T. indica and T. walkeri were in one clade whereas T. controversa, T. caries and T. laevis grouped in a separate clade. Single copy and species-specific genes were identified by orthologous group analysis. Unique species-specific genes were identified and evaluated as suitable markers to differentiate the quarantine and non-quarantine species. After further analyses and manual inspection, primers and probes for the optimum candidate genes were designed and tested in silico, for validation in future wet-lab studies.
\end{abstract}

Keywords: Tilletia indica, Tilletia walkeri, Tilletia controversa, Tilletia caries, Tilletia laevis, Comparative genomics, High throughput next generation sequencing, Phylogenomics

\footnotetext{
* Correspondence: hai.nguyen2@canada.ca; sarah.hambleton@canada.ca ${ }^{1}$ Biodiversity and Bioresources, Ottawa Research and Development Centre, Agriculture and Agri-Food Canada, 960 Carling Ave, Ottawa, Ontario K1A 0C6, Canada

Full list of author information is available at the end of the article
} 


\section{INTRODUCTION}

There are approximately 140 known species in the fungal genus Tilletia (Tilletiales, Ustilaginomycotina), all causing diseases on grass hosts in the Poaceae family. Two of the four species infecting wheat (Triticum), $T$. indica and $T$. controversa (as $T$. 'contraversa'), are subject to quarantine regulations in various countries while $T$. caries and $T$. laevis on wheat and other grasses are also of major concern for agricultural production (Carris et al. 2006). Tilletia species vary in their infection process but sporulation for most occurs in the plant ovary with host tissues in the kernel gradually replaced by masses of darkly pigmented teliospores, so-called "bunt balls". Morphological identification relies on often subtle differences in teliospore colour, size and wall ornamentation, and the presence or absence of a pale sheath (Wilcoxson and Saari 1996). Some diagnostic procedures require spores to be first germinated in the lab which may take several weeks, with success dependent on appropriate growth conditions and spore viability.

Phylogenetic analyses of nuclear ribosomal (rDNA) large subunit sequences (LSU) demonstrated that the four pathogens on wheat and other grasses, and other species occurring on hosts also in the subfamily Pooideae, form a large and well-supported clade within a monophyletic genus (Castlebury et al. 2005). Furthermore, this large clade was subdivided, with $T$. indica and its closest relative $T$. walkeri on ryegrass (Lolium) in their own well-supported sub-clade with identical sequences. The other three wheat-infecting species were grouped with a dozen other species occurring on other hosts, also in a well-supported subclade but with few nucleotide differences amongst species.

Tilletia indica causes the disease of wheat commonly called Karnal bunt. Many countries, including Canada, have a zero tolerance for Karnal bunt spores in wheat seed importations. Symptoms are very difficult to detect in the field and may not be observed until harvest and, although the disease might cause only a small reduction in yield, it reduces grain quality making it unsatisfactory for human consumption (IPPC 2016). During the 1996 National Karnal Bunt Survey in the United States, spores morphologically like those of $T$. indica were discovered in washes derived from wheat seed samples from southeastern states and in forage-mix seed lots from Oregon but no infected wheat seeds were found (Bonde et al. 1997; Cunfer and $>$ Castlebury 1999). Further investigations led to the description of T. walkeri (Castlebury and Carris 1999), a species with similar teliospore morphology but infecting annual ryegrass, which may occur as a weed in areas of wheat production and be present in grain shipments as a contaminant (Castlebury et al. 2005).

Distinguishing $T$. indica from $T$. walkeri (and other species) is essential for international trade activities but morphological identification requires examination of spores by trained mycologists and the two species are very closely related genetically, with ITS fungal barcode sequences differing at only two positions (Levy et al. 2001). The most recent internationally accepted diagnostic protocols for $T$. indica were adopted by the International Plant Protection Convention (IPPC) in 2014 and published in 2016 (IPPC 2016). Of the four molecular methods adopted in that standard, three depend on germination of teliospores for sufficient DNA concentrations (Pimentel et al. 1998; Levy et al. 2001; Frederick et al. 2000). The fourth is a multiplex real-time ITS PCR assay (Tan et al. 2009) for multiple Tilletia species but was designed with an initial PCR amplification step for DNA extracted directly from single crushed teliospores. More recently published LAMP (Loop Mediated Isothermal Amplification) assays target unique regions in the mitochondrial DNA (Gao et al. 2016; Tan et al. 2016).

Tilletia controversa causes dwarf bunt of wheat (DB) and has a restricted distribution while $T$. caries (syn. T. tritici) and T. laevis (syn. T. foetida) both cause common bunt of wheat (CB) and are widely distributed globally in wheat-growing regions. The three species are very closely related genetically and biologically, and cannot be accurately identified using ITS barcodes. While analyses based on ITS, EF1a and RPB2 showed variation among sequences for $\mathrm{DB}$ compared to $\mathrm{CB}$, support was lacking and sampling was limited (Carris et al. 2007). Importantly, $T$. controversa can cause major yield losses and is an internationally quarantined pathogen to prevent its entry to new areas (OEPP/EPPO 2016) and CB, which has been successfully controlled with chemical seed treatments for many years, has made a resurgence under lowinput and organic production (Borgen and Davanlou 2001; Matanguihan et al. 2011; Župunski et al. 2012).

The toolkit of DNA sequence based assays for the regulated species is as yet limited to one or a few options and gene regions, especially for DB (Liu et al. 2009; Zouhar et al. 2010; Gao et al. 2014) and CB (Josefsen and Christiansen 2002; Kochanová et al. 2004) and studies demonstrating their efficacy and specificity during regulatory inspection of field samples are lacking. Thus, despite the known limitations inherent in morphology-based identifications, federal diagnostic labs continue to rely on labour- and timeintensive seed-washing and microscopy techniques (IPPC 2016) to screen grain importations for teliospores of regulated Tilletia species, at least in Canada. Comparative genomics has the potential to identify multiple gene regions that can be targeted for assay development, potentially at hierarchical or tiered levels of phylogenetic resolution and redundancy, to ensure false negatives are avoided and to detect new or novel genotypes.

Although no genome assemblies were publicly available for the genus Tilletia when this study was initiated, there are now genomes for T. indica or T. walkeri (Tan 
et al. 2016; Sharma et al. 2016; Kumar et al. 2017; Kumar et al. 2018) and T. horrida (Wang et al. 2015), but no other species. We have sequenced, annotated and compared the whole genomes of three strains of $T$. indica, two strains of $T$. walkeri, two strains of $T$. controversa, one strain of $T$. caries and two strains of T. laevis. Our objective was to search for candidate genes that were shared amongst, between and within species, in addition to those previously targeted for diagnostics. Of particular interest to achieve in this study was to identify a set of genes unique to each species, as candidate loci for future real time PCR assay development, with the focus on robust differentiation of non-quarantine from quarantined species for regulatory purposes.

\section{MATERIALS AND METHODS}

\section{Growth, DNA/RNA extraction and sequencing}

Ten Tilletia strains representing five Tilletia species were selected for this study: T. caries DAOMC 238032, T. controversa DAOMC 236426 \& DAOMC 238052, T. indica DAOMC 236414, DAOMC 236408 \& DAOMC 236416, $T$. laevis DAOMC 238040 \& ATCC 42080, and T. walkeri DAOMC 236422 \& DAOMC 238049. The DAOMC strains were cultured as polysporidial isolates from surface-sterilized germinated teliospores by the Canadian Food Inspection Agency and most were included in a study by McDonald et al. (2000). They were later provided to Agriculture and Agri-Food Canada as pure cultures for research purposes and for long term preservation in the Canadian Collection of Fungal Cultures (DAOMC) in Ottawa, Canada. The ATCC culture was obtained from the American Type Culture Collection (Manassas, VA USA).

DNA was extracted from mycelia grown on solid potato dextrose agar (PDA; Difco, Becton Dickinson, NJ, USA) at room temperature in the dark and using one of the following kits with the manufacturer's instructions: E.Z.N.A. ${ }^{\circ}$ Fungal DNA Miniprep kit (VWR, Mississauga, ON, Canada), OmniPrep for Fungi kit (G-Biosciences, St. Louis, MO, USA), or Macherey-Nagel Nucleospin 96 Plant or Macherey-Nagel NucleoMag 96 Trace kit (Macherey Nagel GmbH \& Co. KG, Düren, Germany). One representative of each species, except for T. laevis, was also grown for RNA extraction: T. caries DAOMC 238032, T. controversa DAOMC 236426, T. indica DAOMC 236416 and T. walkeri DAOMC 236422. They were grown on solid PDA plates at room temperature in the dark and in three liquid media preparations under natural light at $20^{\circ} \mathrm{C}$ and at $120 \mathrm{rpm}$ on a rotary shaker: T19 medium (customized for Tilletia; Trione 1964), potato-sucrose agar (from diced potatoes; Wilcoxson and Saari 1996), and 2\% Malt agar with trace elements (Samson et al. 2010). RNA was extracted using the Nucleospin $^{\circ}$ RNA L (Midi) or Nucleospin ${ }^{\circ}$ RNA II (Mini) extraction kits (Macherey Nagel GmbH \& Co. KG, Düren,
Germany) following the manufacturer's instructions. DNA quality and quantity were checked using a Qubit $^{\oplus}$ 2.0 Fluorometer (Invitrogen, ThermoFisher Scientific, Waltham, MA USA) on agarose gels and by ITS DNA barcode sequencing (data not shown). RNA quality and quantity were checked with Qubit and a Bioanalyzer (Agilent, Santa Clara, CA USA). Paired end sequencing $(2 \times 101 \mathrm{bp})$ of genomic libraries and RNA libraries of T. caries DAOMC 238032, T. controversa DAOMC 236426, T. indica DAOMC 236416 and T. walkeri DAOMC 236422 was performed on an Illumina HiSeq 2500 at the National Research Council Canada in Saskatoon, Saskatchewan, Canada. Preliminary unpublished versions of these assemblies and annotations were made available on NCBI in 2016 but these data have been superseded by the versions published here. Paired end sequencing $(2 \times 300 \mathrm{bp})$ of genomic libraries of $T$. controversa DAOMC 236426 and DAOMC 238052, $T$. laevis DAOMC 238040 and ATCC 42080, T. indica DAOMC 236408 and DAOMC 236414, and T. walkeri DAOMC 238049 was performed on an Illumina MiSeq at the Molecular Technologies Laboratory at Agriculture and Agri-Food Canada. A total of 20 Illumina libraries were generated. PacBio RS II sequencing of $T$. controversa DAOMC 236426 was performed at Genome Quebec in Montreal using two SMRT cells. The libraries generated in this study are summarized in Additional file 1: Table S1.

\section{Genome assembly and annotation}

Prior to genome assembly, quality of reads from genomic DNA was checked with FastQC v0.10.1 (http:// www.bioinformatics.babraham.ac.uk/projects/fastqc/).

Adaptor sequences and poor quality bases were trimmed with Trimmomatic v.0.36 (Bolger et al. 2014). De novo sequence assembly was performed using SPAdes 3.7.1 (Bankevich et al. 2012), where k-mer sizes were automatically chosen based on input read lengths, with error correction using BayesHammer (Nikolenko et al. 2013) and with mismatch correction enabled. If a strain was sequenced multiple times, all datasets for that strain were specified in one assembly. Scaffolds shorter than $1000 \mathrm{bp}$ were discarded. GapFiller v. 1.10 (Boetzer and Pirovano 2012) was used to close gaps in the scaffolds using the trimmed and corrected paired-end reads from above. Assembly statistics were generated with QUAST v2.3 (Gurevich et al. 2013). The corrected reads were mapped back onto the scaffolds using Bowtie2 v2.0.0 (Langmead and Salzberg 2012) and approximate nucleotide wise coverage was determined with Qualimap v2.2.1 (García-Alcalde et al. 2012).

To perform genome annotation, the quality of the sequenced reads from RNA was checked with FastQC v0.10.1, adaptor sequences and poor quality bases were trimmed with Trimmomatic v.0.36 as described above. 
These trimmed RNA reads were then mapped to the genome of the respective Tilletia species with TopHat v2.0.5 (Kim et al. 2013). RNA reads from T. caries DAOMC 238032 were mapped to the genomes of T. laevis because no RNA data were generated for that species. Following the mapping of RNA to the genome assemblies, gene prediction was performed by BRAKER v1.9 (Hoff et al. 2016) with the fungal option turned on and the alternative splicing determination option turned off. The BUSCO v 2.0 (Simão et al. 2015) program was used to assess genome assembly and annotation completeness with fungal profiles (http://busco.ezlab.org/v2/datasets/ fungi_odb9.tar.gzk).

To determine potential function, the protein sequences from the UniProt/Swiss-Prot manually curated protein data set were compared with the annotated proteins of each Tilletia genome by blastp v2.2.26+ (Camacho et al. 2009). The gene models with BLAST hits having e-value of less than $1.0 \mathrm{E}^{-100}$ and mean similarity hit of $\geq 90 \%$ were assumed to be orthologs and they were given names following recommended conventions (http://www.uniprot.org/docs/proknameprot). Annotations were validated using Genome Annotation Generator (Hall et al. 2014) and tbl2asn (http://www.ncbi.nlm.nih.gov/genbank/ tbl2asn2/) was used to produce GenBank files for subsequent analyses and SQN files for genome submission to
NCBI. Genes predicted from each genome were compared in pairs using MUMmer v. 3.23 (Kurtz et al. 2004). Using the predicted genes nucleotide sequences as input, the Average Nucleotide Identity (ANI) was calculated using FastANI (Jain et al. 2018).

Statistics for all ten Tilletia genomes are summarized in Table 1. Accession numbers for raw NGS data and for genome assemblies/annotations are provided in Additional file 1: Table S1.

\section{Orthologous group analysis}

For each Tilletia genome, genes (that include both exons \& introns) and protein sequences were extracted as fasta files with an online tool (https://rocaplab.ocean.washington.edu/tools/genbank_to_fasta/) using GenBank files as input. Orthologous group analysis was performed with OrthoFinder v1.1.8 (Emms and Kelly 2015), on default settings, using protein sequences from each Tilletia genome as inputs. The mcl program (Enright et al. 2002) is part of the OrthoFinder pipeline and it is used to cluster similar proteins into groups called orthogroups that essentially represent putative gene families. A visual representation was made using InteractiVenn (Heberle et al. 2015) to illustrate the number of orthogroups shared between species and those unique to each species.

Table 1 Genome statistics of Tilletia strains compared in this study

\begin{tabular}{|c|c|c|c|c|c|c|c|c|c|c|}
\hline & T. indica & T. indica & T. indica & T. walkeri & T. walkeri & T. controversa & T. controversa & T. caries & T. laevis & T. laevis \\
\hline $\begin{array}{l}\text { DAOMC culture } \\
\text { number }\end{array}$ & $\begin{array}{l}\text { DAOMC } \\
236408\end{array}$ & $\begin{array}{l}\text { DAOMC } \\
236414\end{array}$ & $\begin{array}{l}\text { DAOMC } \\
236416\end{array}$ & $\begin{array}{l}\text { DAOMC } \\
236422\end{array}$ & $\begin{array}{l}\text { DAOMC } \\
238049\end{array}$ & $\begin{array}{l}\text { DAOMC } \\
236426\end{array}$ & $\begin{array}{l}\text { DAOMC } \\
238052\end{array}$ & $\begin{array}{l}\text { DAOMC } \\
238032\end{array}$ & $\begin{array}{l}\text { DAOMC } \\
238040\end{array}$ & $\begin{array}{l}\text { ATCC } \\
42080\end{array}$ \\
\hline $\begin{array}{l}\text { Isolation } \\
\text { source }\end{array}$ & Triticum & Triticum & Triticum & Lolium & Lolium & Triticum & Triticum & Triticum & Triticum & Triticum \\
\hline $\begin{array}{l}\text { Isolation } \\
\text { location }\end{array}$ & India & Pakistan & Pakistan & $\begin{array}{l}\text { Oregon, } \\
\text { USA }\end{array}$ & $\begin{array}{l}\text { Oregon, } \\
\text { USA }\end{array}$ & $\begin{array}{l}\text { Ontario, } \\
\text { Canada }\end{array}$ & $\begin{array}{l}\text { Ontario, } \\
\text { Canada }\end{array}$ & $\begin{array}{l}\text { Idaho, } \\
\text { USA }\end{array}$ & Australia & $\begin{array}{l}\text { Washington, } \\
\text { USA }\end{array}$ \\
\hline $\begin{array}{l}\text { Sequencing } \\
\text { method }\end{array}$ & $\begin{array}{l}\text { Illumina } \\
\text { MiSeq }\end{array}$ & $\begin{array}{l}\text { Illumina } \\
\text { MiSeq }\end{array}$ & $\begin{array}{l}\text { Illumina } \\
\text { HiSeq }\end{array}$ & $\begin{array}{l}\text { Illumina } \\
\text { HiSeq }\end{array}$ & $\begin{array}{l}\text { Illumina } \\
\text { Miseq }\end{array}$ & $\begin{array}{l}\text { Illumina } \\
\text { HiSeq, } \\
\text { MiSeq, } \\
\text { PacBio }\end{array}$ & $\begin{array}{l}\text { Illumina } \\
\text { MiSeq }\end{array}$ & $\begin{array}{l}\text { Illumina } \\
\text { HiSeq }\end{array}$ & $\begin{array}{l}\text { Illumina } \\
\text { MiSeq }\end{array}$ & $\begin{array}{l}\text { Illumina } \\
\text { MiSeq }\end{array}$ \\
\hline $\begin{array}{l}\text { Number of } \\
\text { scaffolds }\end{array}$ & 2555 & 4624 & 3113 & 1387 & 907 & 3741 & 4243 & 4633 & 4501 & 3961 \\
\hline $\begin{array}{l}\text { Largest scaffold } \\
\text { size }(b p)\end{array}$ & 158,844 & 75,904 & 161,394 & 260,724 & 330,910 & 114,021 & 81,512 & 72,392 & 101,287 & 101,260 \\
\hline N50 in scaffolds & 30,694 & 11,729 & 23,649 & 45,552 & 79,486 & 14,874 & 12,786 & 11,482 & 11,569 & 13,920 \\
\hline Gaps per 100 kb & 41.79 & 14.33 & 54.93 & 22.62 & 20.08 & 96.12 & 43.23 & 80.78 & 101.48 & 31.02 \\
\hline GC (\%) in scaffolds & 54.8 & 55.0 & 54.9 & 54.9 & 54.9 & 56.5 & 56.7 & 56.7 & 56.6 & 56.6 \\
\hline $\begin{array}{l}\text { Total length (Mb) } \\
\text { in scaffolds }\end{array}$ & 29.7 & 29.0 & 29.0 & 24.0 & 24.3 & 29.9 & 28.6 & 28.1 & 28.3 & 28.8 \\
\hline Coverage $^{a}$ & $51 x$ & $45 x$ & $38 x$ & $75 x$ & $46 x$ & $67 x$ & $45 x$ & $52 x$ & $67 x$ & $35 x$ \\
\hline $\begin{array}{l}\text { Number of } \\
\text { gene models }\end{array}$ & 9410 & 9677 & 9664 & 7881 & 7842 & 9887 & 9649 & 9952 & 9651 & 9799 \\
\hline $\begin{array}{l}\text { BUSCO (complete } \\
\text { single copy) }\end{array}$ & $98 \%$ & $93 \%$ & $96 \%$ & $97 \%$ & $98 \%$ & $95 \%$ & $96 \%$ & $92 \%$ & $93 \%$ & $95 \%$ \\
\hline
\end{tabular}




\section{Phylogenomics}

To estimate relationships between the ten Tilletia genomes and to verify the species tree, orthogroups containing single copy genes shared between all Tilletia species were identified. Gene sequences at the nucleotide level were extracted as fasta files with the filterbyname.sh script from BBTools v35 (https://jgi.doe.gov/data-and-tools/bbtools/) where one fasta file was generated per orthogroup. Sequences were aligned with MUSCLE v3.8.31 (Edgar 2004) on default settings. The alignment statistics were measured with AMAS (Borowiec 2016). A maximum likelihood phylogenetic analysis was performed on each alignment with RAxML v8.2.9 (Stamatakis 2014) using the GTRGAMMA model with the fast bootstrap method (option - $\mathrm{f}$ a) and 100 bootstrap replicates. All generated trees were combined together and analysed in ASTRAL-II v4.10.10 (Mirarab and Warnow 2015) to construct a greedy consensus tree.

To estimate the phylogenetic position of Tilletia species in the Ustilagomycotina, we performed a phylogenomic analysis with the methodology described in Spatafora et al. (2016). Protein sequences from 49 fungi (Table 2) were downloaded either from NCBI Genomes or from JGI MycoCosm portal (Grigoriev et al. 2014). Some of the assemblies were not annotated so we performed genome annotation with GeneMark-ES v. 2.3e (Borodovsky and Lomsadze 2011) on these species: Cystobasidiopsis lactophilus JCM 7595, Meira nashicola JCM 18503, Golubevia pallescens JCM 5230, Tilletia horrida QB-1, Pseudozyma tsukubaensis NBRC 1940, Sporisorium iseilematis-ciliati BRIP 60887, Sporisorium scitamineum SSC39B and we validated with GAG/tbl2asn method as described above.

Protein sequences from the input fungal species and our ten Tilletia genomes were searched with hmmsearch from the hmmer3.1b package (Eddy 2009) against the 192 Profile Hidden Markov Models (HMM) built from phylogenetically informative markers in Spatafora et al. (2016). Sequence alignment was performed by profile HMM using hmmalign. Poorly aligned regions were trimmed automatically with trimAl v1.4rev15 (Capella-Gutiérrez et al. 2009). A maximum likelihood phylogenetic analysis was performed using RAxML v8.2.9 (Stamatakis 2014) with the fast bootstrap method (option - $\mathrm{f}$ a) and 100 bootstrap replicates. The best model amino acid substitution (PROTCATAUTO) was called. All generated trees were analyzed in ASTRAL-II v4.10.10 (Mirarab and Warnow 2015) to construct a greedy consensus tree with 100 bootstrap replicates following instructions found at https:// github.com/smirarab/ASTRAL. This was done to evaluate the potential conflicts among genes.

\section{Finding species specific genes for detection assay}

To find candidate genes for species specific detection assays, orthogroups representing single copy genes that are also unique to each Tilletia species were identified from OrthoFinder's output. Of note, because $T$. caries was represented by a single genome, the single copy genes unique to that species were found in the "unassigned" orthogroups in the OrthoFinder results. Using the list of gene names in the OrthoFinder output, sequences were extracted as fasta files with the filterbyname.sh script from BBTools v35 (https://jgi.doe.gov/data-and-tools/bbtools/). To verify that a given orthogroup is really unique to a given species, each fasta file was used as a query for a BLAST search against all Tilletia genes at both the nucleotide and amino acid level. The number of single copy and unique orthogroups found for each species is shown in Table 3. Orthogroups found to be unique at the amino acid level were considered to be better candidates. However, only one orthogroup was found at the amino acid level for T. laevis, so for this species, we considered those found at the nucleotide level as well. The following characteristics were considered to be more desirable in potential genes for designing primers and probes for a detection assay: complete genes (predicted with both start and stop codons) that are in the middle of a scaffold rather than at the periphery; genes that were called with at least one other gene on the same scaffold (e.g., not a singleton on a scaffold); genes that did not contain assembly gaps. These criteria were used to further narrow down the list of candidates from Table 3. Using Geneious R10 (Biomatters Ltd., Auckland, New Zealand), primers and probes were designed using very stringent parameters, with amplicon size between $100 \mathrm{bp}$ to $150 \mathrm{bp}$ and inside an exon, primers with a $\mathrm{T}_{\mathrm{m}}$ of approximately $60^{\circ} \mathrm{C}$ and roughly $23 \mathrm{bp}$ long, and probes with a $\mathrm{T}_{\mathrm{m}}$ of approximately $70^{\circ} \mathrm{C}$ and roughly $27 \mathrm{bp}$ long. The suggested primers and probes sequences for each candidate gene are reported in Table 4. These primers and probes were mapped back to all genome assemblies using the Geneious R10 mapper to verify that there was no potential cross reactivity to a species they were not designed to amplify. For each candidate gene, the protein sequence was analyzed with InterProScan (Finn et al. 2017) using the online tool at EMBL-EBI on April 14, 2018 (https://www.ebi. ac.uk/interpro/search/sequence-search), as well as blastp against the NCBI $\mathrm{nr}$ database on April 10, 2019, to find its putative function. Each candidate gene was analyzed with EffectorP 2.0 (Sperschneider et al. 2018), hosted on http://effectorp.csiro.au on April 10, 2019.

\section{RESULTS}

\section{Genome sequencing, assembly and annotation}

The raw sequencing data were assembled de novo into 907 to 4633 scaffolds with GC content from 54.8 to $56.7 \%$ and $\mathrm{N} 50$ from $11.5 \mathrm{~Kb}$ to $79.5 \mathrm{~Kb}$. Notably, the genome assembly size ranged anywhere from smaller $24 \mathrm{Mb}$ for $T$. walkeri to larger $28.1 \mathrm{Mb}$ to $29.9 \mathrm{Mb}$ for $T$. caries, 
Table 2 List of genomes used for phylogenetic analysis in current study

\begin{tabular}{|c|c|c|c|}
\hline Phylum & Name & Source of Genome Data & Reference \\
\hline Basidiomycota & Acaromyces ingoldii MCA 4198 v1.0 & JGI MycoCosm & Kijpornyongpan et al. 2018 \\
\hline Basidiomycota & Agaricus bisporus var. bisporus H97 v2.0 & JGl MycoCosm & Morin et al. 2012 \\
\hline Basidiomycota & Auricularia subglabra v2.0 & JGl MycoCosm & Floudas et al. 2012 \\
\hline Basidiomycota & Ceraceosorus guamensis MCA 4658 v1.0 & JGI MycoCosm & Kijpornyongpan et al. 2018 \\
\hline Basidiomycota & Cystobasidiopsis lactophilus JCM 7595 & NCBI (BCIO01000001.1) ${ }^{a}$ & Manabe et al. unpublished \\
\hline Basidiomycota & Exobasidium vaccinii MPITM v1.0 & JGI MycoCosm & Spatafora et al. unpublished \\
\hline Basidiomycota & Golubevia pallescens JCM 5230 & NCBI (BCHO01000001.1) ${ }^{a}$ & Manabe et al. unpublished \\
\hline Basidiomycota & Jaminaea sp. MCA 5214 v1.0 & JGl MycoCosm & Kijpornyongpan et al. 2018 \\
\hline Basidiomycota & Malassezia globosa & JGl MycoCosm & Xu et al. 2007 \\
\hline Basidiomycota & Malassezia sympodialis ATCC 42132 & JGl MycoCosm & Gioti et al. 2013 \\
\hline Basidiomycota & Meira miltonrushii MCA 3882 v1.0 & JGI MycoCosm & Kijpornyongpan et al. 2018 \\
\hline Basidiomycota & Meira nashicola JCM 18503 & NCBI (BCJU01000001.1) ${ }^{a}$ & Manabe et al. unpublished \\
\hline Basidiomycota & Melanotaenium endogenum CBS 481.91 v1.0 & JGl MycoCosm & Spatafora et al. unpublished \\
\hline Basidiomycota & Mixia osmundae IAM 14324 v1.0 & JGI MycoCosm & Toome et al. 2014b \\
\hline Basidiomycota & Moesziomyces antarcticus DSM 70725 & JGl MycoCosm & Lorenz et al. 2014 \\
\hline Basidiomycota & Moesziomyces aphidis DSM 70725 & JGI MycoCosm & Lorenz et al. 2014 \\
\hline Basidiomycota & Pseudozyma hubeiensis SY62 & JGI MycoCosm & Konishi et al. 2013 \\
\hline Basidiomycota & Pseudozyma tsukubaensis NBRC 1940 & NCBI (MAIP00000000.1) ${ }^{a}$ & Geiser et al. 2016 \\
\hline Basidiomycota & Puccinia striiformis f. sp. tritici PST-130 & JGI MycoCosm & Cantu et al. 2011 \\
\hline Basidiomycota & Sporisorium iseilematis-ciliati BRIP 60887 & NCBI (MJEU000000000.1) a & Geiser et al. 2016 \\
\hline Basidiomycota & Sporisorium reilianum SRZ2 & JGl MycoCosm & Schirawski et al. 2010 \\
\hline Basidiomycota & Sporisorium scitamineum SSC39B & NCBI (CP010913.1) ${ }^{a}$ & Taniguti et al. 2015 \\
\hline Basidiomycota & Testicularia cyperi MCA 3645 v1.0 & JGl MycoCosm & Kijpornyongpan et al. 2018 \\
\hline Basidiomycota & Tilletia caries DAOMC 238032 & & current study \\
\hline Basidiomycota & Tilletia controversa DAOMC 236426 & & current study \\
\hline Basidiomycota & Tilletia controversa DAOMC 238052 & & current study \\
\hline Basidiomycota & Tilletia horrida QB-1 & NCBI (LAXH01000001.1) a & Wang et al. 2015 \\
\hline Basidiomycota & Tilletia indica DAOMC 236408 & & current study \\
\hline Basidiomycota & Tilletia indica DAOMC 236414 & & current study \\
\hline Basidiomycota & Tilletia indica DAOMC 236416 & & current study \\
\hline Basidiomycota & Tilletia laevis ATCC 42080 & & current study \\
\hline Basidiomycota & Tilletia laevis DAOMC 238040 & & current study \\
\hline Basidiomycota & Tilletia walkeri DAOMC 236422 & & current study \\
\hline Basidiomycota & Tilletia walkeri DAOMC 238049 & & current study \\
\hline Basidiomycota & Tilletiaria anomala UBC 951 v1.0 & JGl MycoCosm & Toome et al. 2014a \\
\hline Basidiomycota & Tilletiopsis washingtonensis MCA 4186 v1.0 & JGl MycoCosm & Kijpornyongpan et al. 2018 \\
\hline Basidiomycota & Tremella mesenterica Fries v1.0 & JGl MycoCosm & Floudas et al. 2012 \\
\hline Basidiomycota & Ustilago hordei Uh4857_4 & JGl MycoCosm & Laurie et al. 2012 \\
\hline Basidiomycota & Ustilago maydis 521 v2.0 & JGl MycoCosm & Kämper et al. 2006 \\
\hline Basidiomycota & Violaceomyces palustris SA 807 v1.0 & JGl MycoCosm & Kijpornyongpan et al. 2018 \\
\hline Basidiomycota & Wallemia ichthyophaga EXF-994 & JGl MycoCosm & Zajc et al. 2013 \\
\hline Ascomycota & Neurospora crassa OR74A v2.0 & JGI MycoCosm & Galagan et al. 2003 \\
\hline Ascomycota & Saccharomyces cerevisiae S288C & JGl MycoCosm & Goffeau et al. 1996 \\
\hline Ascomycota & Schizosaccharomyces pombe & JGl MycoCosm & Wood et al. 2002 \\
\hline
\end{tabular}


Table $\mathbf{2}$ List of genomes used for phylogenetic analysis in current study (Continued)

\begin{tabular}{|c|c|c|c|}
\hline Phylum & Name & Source of Genome Data & Reference \\
\hline Blastocladiomycota & Allomyces macrogynus ATCC 38327 v1.0 & JGI MycoCosm & Nordberg et al. 2013 \\
\hline Blastocladiomycota & Blastocladiella cf. britannica JEL711 & JGI MycoCosm & James et al. unpublished \\
\hline Blastocladiomycota & Catenaria anguillulae PL171 v1.0 & JGI MycoCosm & Mondo et al. 2017 \\
\hline Chytridiomycota & Gaertneriomyces semiglobifer Barr 43 v1.0 & JGI MycoCosm & James et al. unpublished \\
\hline Chytridiomycota & Globomyces pollinis-pini Arg68 v1.0 & JGI MycoCosm & James et al. unpublished \\
\hline Chytridiomycota & Neocallimastix californiae G1 v1.0 & JGI MycoCosm & Haitjema et al. 2017 \\
\hline Cryptomycota & Rozella allomycis CSF55 v1.0 & JGI MycoCosm & James et al. 2013 \\
\hline Mucoromycota & Mortierella elongata AG-77 v2.0 & JGI MycoCosm & Uehling et al. 2017 \\
\hline Mucoromycota & Mucor circinelloides CBS 277.49 v2.0 & JGI MycoCosm & Corrochano et al. 2016 \\
\hline Mucoromycota & Phycomyces blakesleeanus NRRL1555 v2.0 & JGI MycoCosm & Corrochano et al. 2016 \\
\hline Mucoromycota & Rhizophagus irregularis DAOM 181602 v1.0 & JGl MycoCosm & Tisserant et al. 2013 \\
\hline Mucoromycota & Rhizopus oryzae v1.0 & JGI MycoCosm & Ma et al. 2009 \\
\hline Zoopagomycota & Basidiobolus meristosporus CBS 931.73 v1.0 & JGl MycoCosm & Mondo et al. 2017 \\
\hline Zoopagomycota & Coemansia reversa NRRL 1564 v1.0 & JGI MycoCosm & Chang et al. 2015 \\
\hline Zoopagomycota & Conidiobolus coronatus NRRL 28638 v1.0 & JGI MycoCosm & Chang et al. 2015 \\
\hline
\end{tabular}

${ }^{a}$ Denotes genomes that we annotated in this study because no annotations were available at the time of our analyses

T. controversa, T. laevis and T. indica. Between 92 and 98\% of complete BUSCO's were detected in all genomes suggesting that a significant portion of the total genomic information was successfully recovered. We predicted 7842 to 9952 gene models, depending on the species. The results are tabulated in Table 1.

\section{Genomic comparison}

Pairwise comparisons, by alignments of the genes, were performed to qualitatively assess similarities between Tilletia genomes and the Average Nucleotide Identity (ANI) was calculated for each pair in order to quantify similarity (Fig. 1). Gene sequences and gene content of individuals from the same species are expected to be the most similar, where almost all genes can be aligned. Species in different species complexes should share the least amount of genomic information and thus only the core Tilletia genes will be aligned. As expected, the mummerplots qualitatively show that $T$. indica and $T$. walkeri are well aligned with each other, as expected since they are closely related whereas $T$. controversa, $T$. caries and $T$. laevis are well aligned with each other as they reside in a separate species complex. Of note, the genome size of $T$. indica is roughly $29-30 \mathrm{Mb}$ while the genome size of $T$. walkeri is only $24 \mathrm{Mb}$. In Fig. 1, the T. indica and T. walkeri gene regions are aligned but it appears that $T$. indica has extraneous sequences that $T$. walkeri does not have. This is confirmed by the fact that $T$. indica has thousands more gene models predicted than T. walkeri (Table 1). As for T. controversa, T. caries and T. laevis, they all roughly have the same genome sizes and are well aligned.

The ANI score is the average nucleotide identity shared between any two genomes (Richter and Rossello-Mora 2009) and it is an accepted metric for delimiting bacterial species. It was found that comparison of the same species should yield an ANI of > 95\% (Goris et al. 2007; Richter and Rossello-Mora 2009; Jain et al. 2018). This might be a good rule of thumb to determine intra-species and inter-species boundaries. Because our mummerplots can only provide qualitative measures of similarity, we calculated the ANI score for each pair to quantify the similarities. Following the same qualitative trend as the mummerplots, the ANI score was highest when comparing strains of the same species or

Table 3 Number of unique single copy genes of each Tilletia species after the all versus all BLAST verification step

\begin{tabular}{llcc}
\hline & & Number of single copy genes unique to a given species \\
\cline { 2 - 3 } Species & Strains considered & at the nucleotide level & at the amino acid level \\
Tilletia controversa & DAOMC 238032 & 377 & 72 \\
Tilletia laevis & DAOMC 236426, DAOMC 238052 & 35 & 2 \\
Tilletia indica & DAOMC 238040, ATCC 42080 & 13 & 1 \\
Tilletia walkeri & DAOMC 236416, DAOMC 236408, DAOMC 236414 & 61 & 2 \\
\hline
\end{tabular}




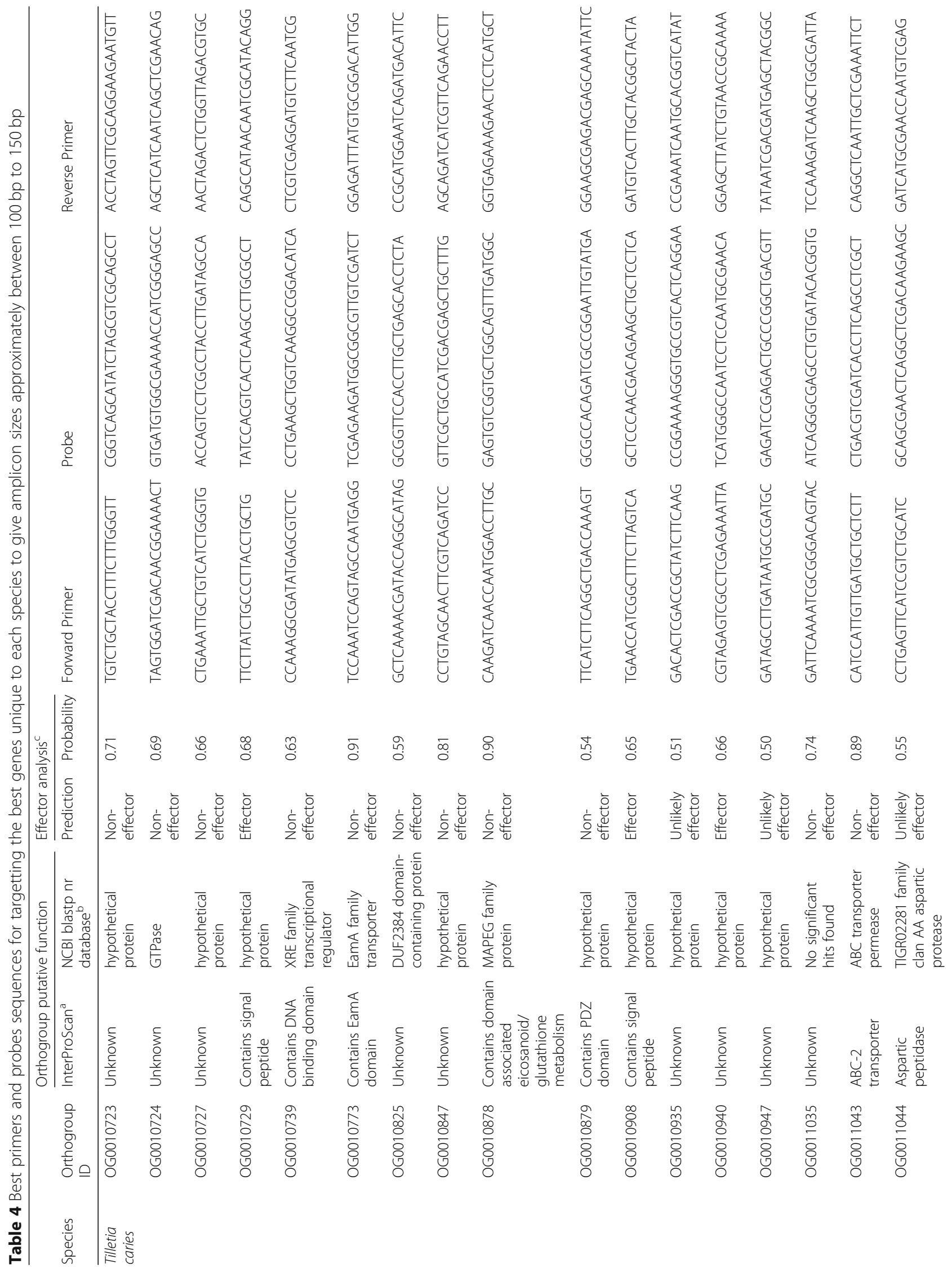




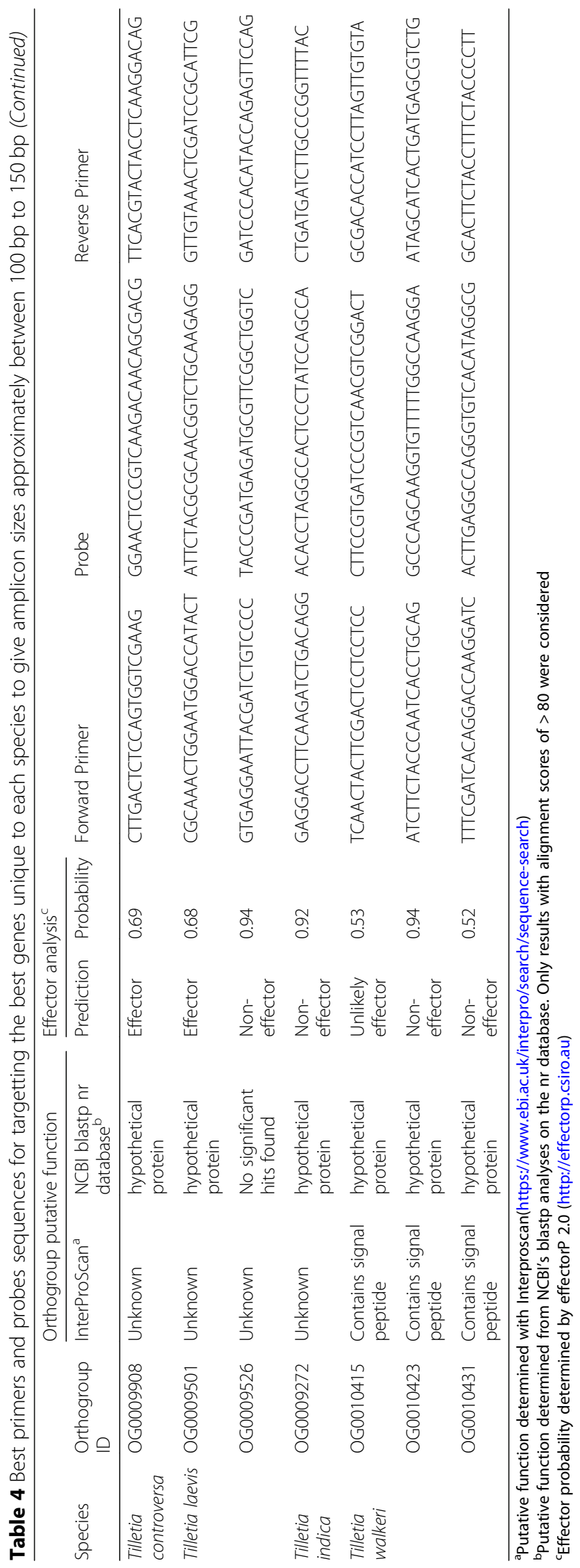


strains of species within a species complex $(>95 \%)$ and was lower when strains from different species complexes were compared $(<80 \%)$. Determination of ANI is not yet common practice in mycology. Recently, Lastovetsky et al. (2016) found an ANI of $92 \%$ when comparing two strains of Rhizopus microspores but there are not enough examples yet to find a general rule of thumb for delimiting species.

All protein sequences extracted from the ten Tilletia genomes were grouped into 10526 orthogroups. There were 6164 orthogroups that were shared among all Tilletia species. Of those, 4896 orthogroups were considered single copy genes, where one representative sequence was found per genome for that given orthogroup. Notably, there were 1249 orthogroups shared between T. caries, T. controversa and $T$. laevis. There were 741 orthogroups shared between $T$. indica and $T$. walkeri. The number of shared orthogroups between species is illustrated in Fig. 2 as a Venn diagram.

\section{Evolutionary relationships: species tree and phylogenetic placement in kingdom Fungi}

There is an underlying phylogenetic signal that represents the true species tree even though different parts of the genome can have different evolutionary histories leading to conflicts in gene trees. Using the sequences from the 4896 single copy genes shared among all ten Tilletia genomes, representing about half of the total gene models predicted, we estimated the consensus species tree using a coalescence-based method with multi-locus bootstrapping (Fig. 3) and with Rozella allomycis as the outgroup taxon. From these single copy loci, the total alignment length was $12.2 \mathrm{Mb}$. The total number of bases in the matrix was $120 \mathrm{Mb}(12.2 \mathrm{Mb} \times 10$ Tilletia genomes), where roughly $10 \%$ of those bases were gaps. For these 4896 genes, there were 2.6 million parsimony informative sites detected and the average proportion of parsimony informative sites is 0.22 . This means roughly a little over one fifth of each gene contained variation useful for phylogenetic reconstruction. Based on the analysis of these 4896 genes, our concept of the Tilletia phylogenetic species is supported because each Tilletia species grouped together in a clade with $100 \%$ bootstrap support, confirming the identification using traditional Sanger sequencing (data not shown) and the results of McDonald et al. (2000) with repPCR DNA fingerprinting for the same DAOMC strains included in that study. It also shows the two distinct species complexes: T. indica and T. walkeri in one group, and T. controversa, T. caries and T. laevis in the second group.

We performed a phylogenomic analysis using protein sequences from 192 core conserved orthologous proteins to place Tilletia in the fungal kingdom (Fig. 4). This tree shows Tilletia in the Ustilaginomycotina and in the Exobasidiomycetes as expected. Our Tilletia genomes grouped with $T$. horrida in a well-supported clade representing the Tilletiales. The remaining taxa sampled in the class are classified in other orders. In this analysis, $T$. horrida is basal to our sequenced Tilletia species, which is not in conflict with the LSU analysis of Castlebury et al. (2005). These 192 genes were sufficient in separating the two Tilletia species complexes into two well-supported clades. They were not able to resolve some of the backbone nodes in the Exobasidiomycetes but groupings at the order level were consistent with the comprehensive genomics analyses of Ustilaginomycotina by Kijpornyongpan et al. (2018), except that theirs lacked any Tilletiales.

\section{Candidate markers for detection assay}

Given the implications for trade and the export of commodities, the genes used in an assay for regulatory purposes should be precise at differentiating closely related species. The orthologous group analysis revealed some initial single copy genes that were considered unique to each species but also exist in all sequenced strains of the corresponding species: there were 535 for T. caries, 125 for T. controversa, 64 for T. laevis, 144 for T. indica, 136 for T. walkeri. After performing an allversus-all BLAST search, at the nucleotide and amino acid level, as another verification step to ensure that no parts of the so-called unique genes in one species would be similar to some genes in another species, the list was narrowed down to fewer candidates (Table 3). Genes considered unique at the amino acid level were further investigated manually first. At this stage, there was only 1 such candidate for T. laevis. Upon further manual inspection, this candidate gene turned out to be unsuitable because it is too similar to a genomic region in $T$. caries. Thus we started looking at the 13 candidates of T. laevis that were found to be unique at the nucleotide level. After manual inspection and verification, only a few candidates with appropriate primer/probe sites were identified and suggested for further wet lab validation in a future study: one for T. controversa, two for T. laevis, one for T. indica, three for T. walkeri and seventeen for T. caries (Table 4). The designed primers and probes were mapped back to all genome assemblies, including those of $T$. indica (Sharma et al. 2016; Kumar et al. 2017; Kumar et al. 2018) and T. horrida (Wang et al. 2015) available on $\mathrm{NCBI}$, and were found to be indeed unique for detecting the intended species for which they were designed (data not shown). To assign putative function to these candidate genes, we analyzed the protein sequence with InterProScan. Interestingly, some of the genes have totally unknown functions and some contain a signal peptide.

\section{DISCUSSION}

The detection of quarantine Tilletia species on wheat is an important issue tied to trade (IPPC 2016; OEPP/EPPO 

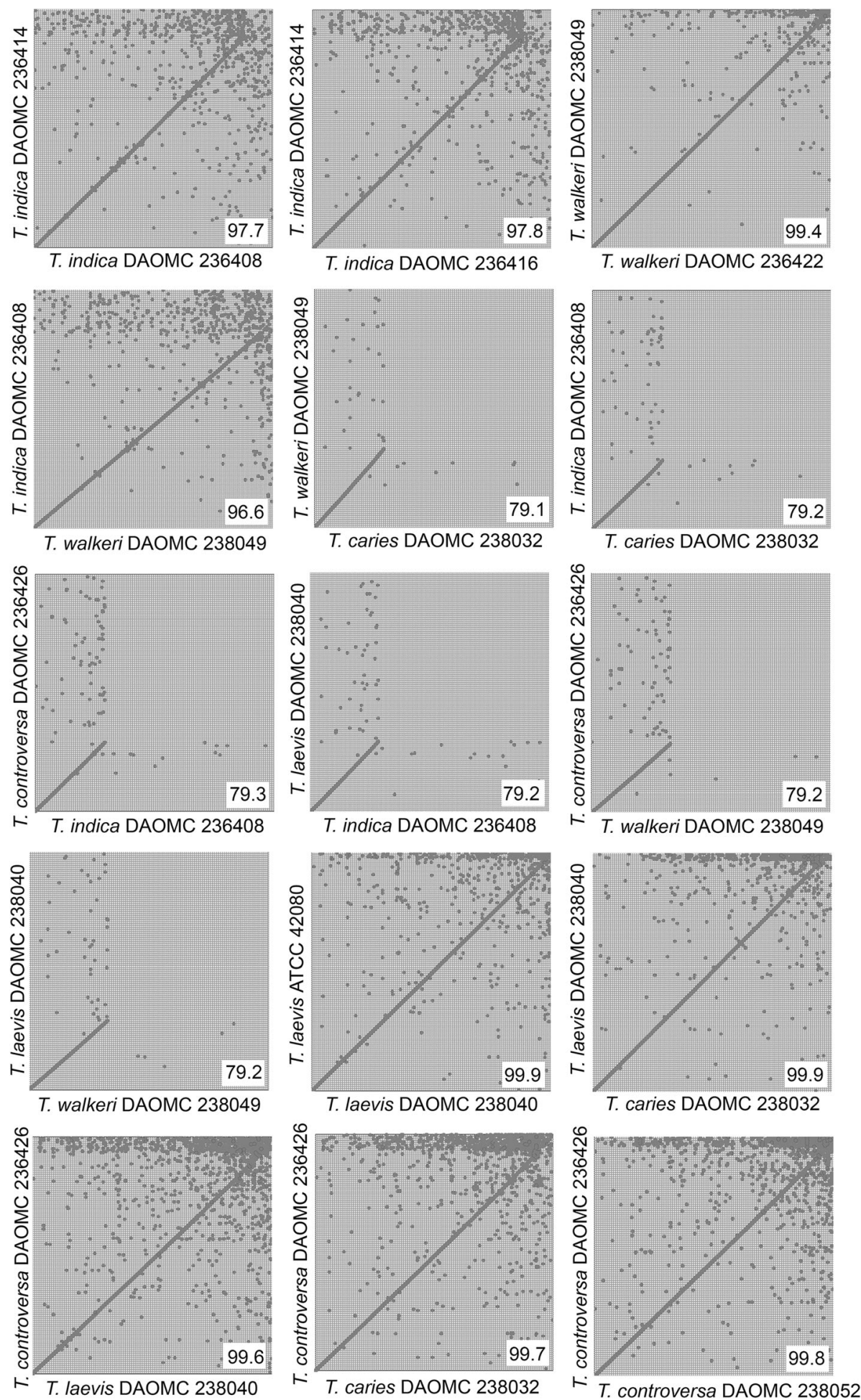

Fig. 1 Mummerplots. Genes predicted from each genome were compared by alignment and the Average Nucleotide Identity (ANI) is shown in the bottom right corner of each comparison 


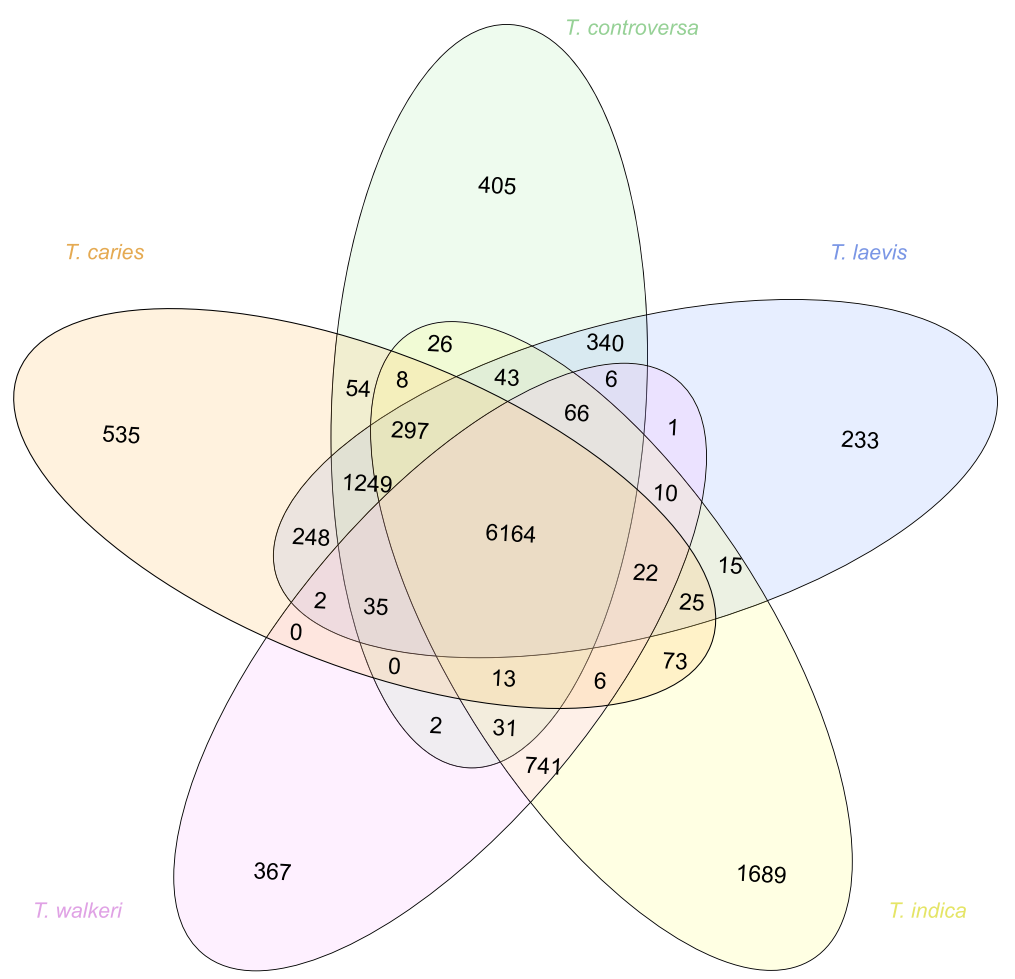

Fig. 2 Unique and shared orthogroups between the five Tilletia species from OrthoFinder's output

2016). In this study, we sequenced new genomes for $T$. indica and the first genomes for four other Tilletia species, performed phylogenomics analyses to confirm relationships, and then queried the data to identify species-specific gene regions that could be exploited for regulatory diagnostics (Table 4). Many of the DNA-based assays already published for this purpose were developed without the use of genomics data and rely on targeting commonly studied gene regions that either can easily be sequenced with existing primers or are represented in publicly available sequence databases. Those assays include real time PCR protocols probing the LSU region for T. caries (McNeil et al. 2004) or the ITS region for T. indica (Tan and Murray 2006; Tan et al. 2009; Thirumalaisamy et al. 2011; Gurjar et al. 2017). This approach uses 'small data' and although sometimes adequate, it might not result in extremely specific diagnostic assays. In our study, we harnessed the power of comparative genomics and 'big data', to perform an exhaustive search to find alternate markers that should be in theory more robust for diagnostic assays of

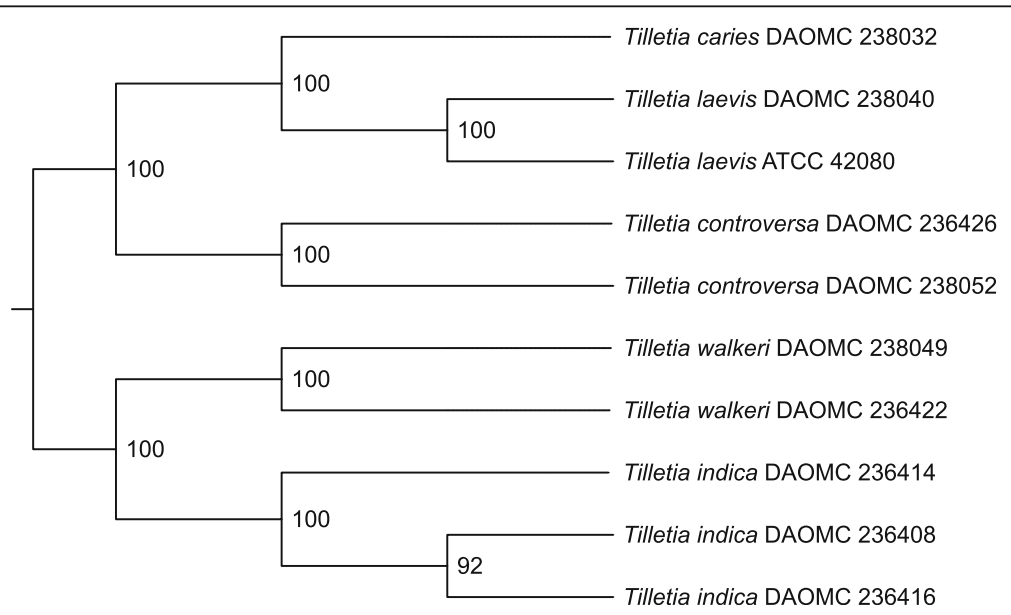

Fig. 3 ASTRAL greedy consensus cladogram based on analyses of individual bootstrap trees of the 4896 single copy orthologous genes shared between the ten Tilletia strains. Support values show the percentage of bootstrap replicates that contain that branch 


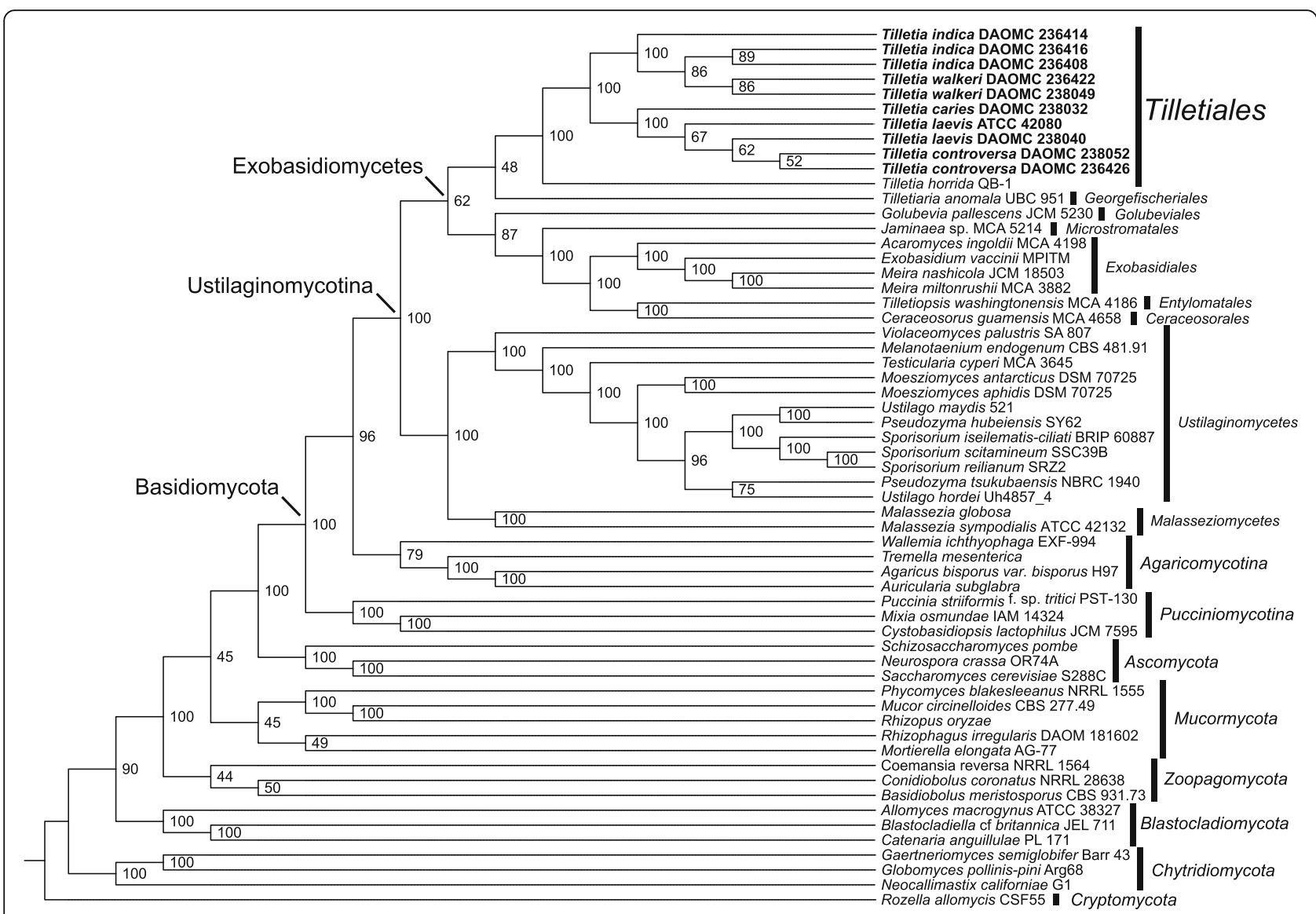

Fig. 4 ASTRAL greedy consensus cladogram based on analyses of individual bootstrap trees for each of 192 conserved orthologous proteins placing Tilletia in Kingdom Fungi. Support values show the percentage of bootstrap replicates that contain that branch

quarantine species. Targeting genes unique to the species of interest increases the likelihood of sustainable specificity.

Currently there are six other genomes listed on GenBank for $T$. indica strains, all originating from India, none with annotations. Two are unpublished and the other four were published too recently to be included in our analyses (Sharma et al. 2016, Kumar et al. 2017, Kumar et al. 2018). There is also a genome for one T. horrida strain (Wang et al. 2015) originating from China. Our study adds data resources for this genus with both the genome assemblies and genome annotations of three $T$. indica strains originally from India or Pakistan, two T. walkeri from the USA, two $T$. controversa from Canada, one T. caries from the USA and two T. laevis from the USA or Australia. An earlier assembly of our genome for T. indica DAOMC 236416, made available in 2016, has already been used to help improve the $T$. indica draft genome assembly of Kumar et al. (2018).

Rather than focus on analyses of effectors and CAZymes, as has been done by others (Kumar et al. 2017; Kijpornyongpan et al. 2018), we chose to focus our efforts on finding a comparative genomics approach to analyze the data contained in the ten Tilletia genomes and to find unique genes for the design of detection assays, which is something that previously could not be investigated for Tilletia. The draft assembly of $T$ indica strain TiK_1, reported by Kumar et al. (2017), contained 10957 contigs and an improved assembly of the same strain was published later with 787 scaffolds (Kumar et al. 2018), whereas our T. indica genomes were assembled into 2555 to 4624 scaffolds. Kumar et al. (2017) reported about 11500 gene models annotated without transcriptome data. In the improved assembly of strain TiK_1, those authors also obtained 9209 protein coding gene models, but it was unclear whether transcriptome data was considered in the annotation procedure. We obtained roughly 9500 gene models using transcriptome data. The T. indica TiK_1 strain was not included in our analyses because the annotations were not available for download and we already had data for three strains of $T$. indica collected in different years or different countries, which were adequate to achieve our objective. To verify that this did not result in excluding a strain of $T$. indica that was genetically divergent to our strains, we performed a core genome alignment and phylogeny, using Parsnp (Treangen et al. 2014), 
and found that $T$. indica TiK_1 groups together in one phylogenetic clade with all of our T. indica strains (Nguyen unpublished data), thus confirming that adding TiK_1 would not likely have further improved our results.

The genomes of $T$. walkeri from our study are an important contribution for future in-depth genomic studies focused on T. walkeri and T. indica. Although their ITS sequences are almost identical, their genomes are markedly different in size, at approximately $30 \mathrm{Mb}$ for Tilletia indica and about $24 \mathrm{Mb}$ for T. walkeri. Our genome annotation indicates that $T$. indica has thousands of extra genes compared to its sister species (Table 1, Fig. 1 ), and the importance of these genes could be investigated further, eg. for potential roles in pathogenicity. The study by Kijpornyongpan et al. (2018) included analyses of gene conservation among members of the Ustilaginomycotina and found that the pathogenicity genes previously identified for Ustilago maydis were limited in distribution among the genomes of other taxa. Their analyses lacked representatives from the Tilletiales, but the authors hypothesized that fungi in this order would also lack these genes, and may have developed alternative mechanisms. We performed a preliminary analysis on our genome annotations (Nguyen unpublished data) employing the same detection methodology, and found that the Tilletia species sequenced from this study lack the known smut pathogenicity genes, except for the Srt1-high affinity sucrose transporter (gene UM02374 in $U$. maydis). This would be another potential avenue for investigation in future genetic studies.

The five species clustered into well-supported clades in the phylogenetic analysis with 4896 single copy orthologous genes (Fig. 3), suggesting that our concept of the phylogenetic species in these two complexes held together with multi-locus genome data. After performing manual verification, we proposed primers and probes for a reduced list of species-specific genes (Table 4). We only sequenced one strain of $T$. caries so these 17 suggested candidate markers may not actually exist in all strains of $T$. caries in nature and could be unique to DAOMC 238032. Each of the other species had two or more sequenced genomes so the suggested genes should be more robust. We performed an InterProScan analysis and a blastp analysis against the NCBI nr database to attempt to predict the function of these genes. Many of them had unknown function while few contained a signal peptide at the $\mathrm{N}$ terminus. Some were predicted by EffectorP 2.0 to be effectors with probabilities between 0.65 and 0.69 . Generally, families of candidate effectors were identified on the basis of predicted $\mathrm{N}$-terminal signal peptides, their small size, and lack of similarity to other proteins (Petre and Kamoun 2014). However, these predictions are strictly in silico and functional wet lab experiments would need to be carried out to validate real function.
One prerequisite for the development of robust, sensitive and specific assays is a comprehensive understanding of the systematic and biological relationships of the targets and their closest relatives. Species concepts should be clearly defined and the strains used in the design of any diagnostic assay accurately identified. This aspect remains a challenge for the $\mathrm{DB}$ and $\mathrm{CD}$ pathogens given their propensity for hybridization with each other and with some other Tilletia species. Conspecificity of the DB pathogen and the two CB species was proposed by Russell and Mills (1994), based on results of previous and new genetic, biochemical, physiologic and morphological data, and discussed by others (Shi et al. 1996; Bao 2010). Inter-species hybridization among the DB and CB species was postulated to explain observed morphological intermediates (Wilcoxson and Saari 1996) but also demonstrated in the laboratory in planta or axenic culture (Trail and Mills 1990), between those species and T. fusca (Carris and Gray 1994) and between DB and T. bromi (Pimentel et al. 2000). Comprehensive population genetics studies, which have so far been limited to RAPD and RFLP methods, also provided evidence of natural hybridization among the 95 isolates tested, representing DB, CB and T. fusca var. bromitectorum (Shi et al. 1996). Despite these findings, which underscore the challenges for accurate diagnostics, DB and $\mathrm{CB}$ continue to be considered distinct, in large part because of differences in disease etiology and perceived risk (Wilcoxson and Saari 1996). Treating them as distinct phylogenetic species is supported by our phylogenomics analysis (Fig. 3) where there is strong bootstrap support for $\mathrm{CB}$ as one clade and $\mathrm{DB}$ as a separate clade.

A second prerequisite is acquiring a sufficient number of representatives of varied provenance so that assay validation is tested against a broad sampling of genotypic variation. Progress is an iterative process as samples and data resources are compiled and analyzed. The next step is to gather sufficient numbers of field samples of the wheatassociated Tilletia species and their close relatives for validation testing of these markers and other markers not selected by our methods for screening the genes recovered in our orthologous groups analysis. Adding redundancy by identifying a set of markers or gene regions for development of multiple assays at more than one level of phylogenetic resolution would increase confidence in diagnostic assessments by providing checks against false negatives and for previously unknown or undetected genomic variation. Comparative genomics is the most promising approach for accomplishing this goal. In addition, it was envisioned that the genomic resources generated in this study would contribute in the future to other assay development efforts using SNP (single nucleotide polymorphism) discovery and also to population genetics studies of the $\mathrm{DB} / \mathrm{CB}$ species complex. 


\section{CONCLUSION}

We sequenced and annotated ten genomes of five Tilletia species in two separate species complexes: three strains of T. indica and two strains of T. walkeri in one complex, and two strains of $T$. controversa, one strain of $T$. caries and two strains of $T$. laevis in another complex. Through comparative genomic approaches, we identified gene candidates, and designed primers and probes that are potentially suitable for differentiating each species and are to be validated in future wet-lab studies.

\section{Additional file}

Additional file 1: Table S1. NGS datasets generated in the study. (XLSX $12 \mathrm{~kb})$

\section{Abbreviations}

ANI: Average Nucleotide Identity; CB: Common Bunt; DB: Dwarf Bunt

\section{Acknowledgements}

We thank and acknowledge: the Canadian Food Inspection Agency for providing Tilletia strains, Jeff Cullis for performing some of the preliminary bioinformatics analyses; Raymond Tropiano, Kathryn Temple, Julie Carey, Ekaterina Ponomareva, Quinn Eggertson, Sylvia Wilson and Tara Rintoul for technical assistance in RNA and DNA extraction; Kasia Dadej for performing Illumina MiSeq sequencing; Guillaume Bilodeau and Jeremy Dettman, for reviewing an early draft of the manuscript.

\section{Adherence to national and international regulations}

Tilletia strains in this study were acquired by the Canadian Food Inspection Agency or the American Type Culture Collection (ATCC).

\section{Authors' contributions}

HDTN, TS and PK performed the bioinformatic analyses; HDTN, TS and SH interpreted the results; HDTN and SH drafted the manuscript; all authors read, revised and approved the manuscript; SH acquired the funding, maintained the fungal cultures, and generated the DNA for genome sequencing.

\section{Funding}

This study was funded by Agriculture and Agri-Food Canada grant J-000985 "Next generation sequencing of quarantine crop pathogens" with additional support from the Canadian Safety and Security Program grant CRTI 09-462RD.

\section{Availability of data and materials}

Sequencing data are uploaded to NCBI and accession numbers listed in Additional file 1: Table S1. Cultures listed in Table 1 are deposited in the Canadian Collection of Fungal Cultures (DAOMC) or the American Type Culture Collection (ATCC).

\section{Ethics approval and consent to participate}

Not applicable.

\section{Consent for publication}

Not applicable.

\section{Competing interests}

The authors declare that they have no competing interests.

\section{Author details}

'Biodiversity and Bioresources, Ottawa Research and Development Centre, Agriculture and Agri-Food Canada, 960 Carling Ave, Ottawa, Ontario K1A 0C6, Canada. ${ }^{2}$ Present Address: Research Farm - Vineland, London Research and Development Centre, Agriculture and Agri-Food Canada, 4902 Victoria Avenue N., Vineland Station, Ontario LOR 2E0, Canada. ${ }^{3}$ Present Address: NHP Research Alliance, College of Biological Sciences, University of Guelph, 50 Stone Road East, Guelph, Ontario N1G 2W1, Canada.
Received: 2 April 2019 Accepted: 6 June 2019

Published online: 24 July 2019

\section{References}

Bankevich A, Nurk S, Antipov D, Gurevich AA, Dvorkin M et al (2012) SPAdes: a new genome assembly algorithm and its applications to single-cell sequencing. J Comput Biol 19:455-477

Bao X (2010) Host specificity and phylogenetic relationships among Tilletia species infecting wheat and other cool season grasses. In: PhD thesis, Department of Plant Pathology, Washington State University, USA

Boetzer M, Pirovano W (2012) Toward almost closed genomes with GapFiller. Genome Biol 13:R56

Bolger AM, Lohse M, Usadel B (2014) Trimmomatic: a flexible trimmer for Illumina sequence data. Bioinformatics 30:2114-2120

Bonde MR, Peterson GL, Schaad NW, Smilanick JL (1997) Karnal bunt of wheat. Plant Dis 81:1370-1377

Borgen A, Davanlou M (2001) Biological control of common bunt (Tilletia tritici). J Crop Production 3:157-171

Borodovsky M, Lomsadze A (2011) Gene identification in prokaryotic genomes, phages, metagenomes, and EST sequences with GeneMarkS suite. Curr Protoc Bioinformatics 35:4.5.1-4.5.17

Borowiec ML (2016) AMAS: a fast tool for alignment manipulation and computing of summary statistics. PeerJ 4:e1660

Camacho C, Coulouris G, Avagyan V, Ma N, Papadopoulos J et al (2009) BLAST+: architecture and applications. BMC Bioinformatics 10:421

Cantu D, Govindarajulu M, Kozik A, Wang M, Chen X et al (2011) Next generation sequencing provides rapid access to the genome of Puccinia striiformis $\mathrm{f}$. $\mathrm{sp}$. tritici, the causal agent of wheat stripe rust. PLoS One 6:e24230

Capella-Gutiérrez S, Silla-Martínez JM, Gabaldón T (2009) trimAl: a tool for automated alignment trimming in large-scale phylogenetic analyses. Bioinformatics 25:1972-1973

Carris L, Gray P (1994) The ability of Tilletia fusca to hybridize with the wheat bunt species under axenic conditions. Mycologia 86:157-163

Carris LM, Castlebury LA, Goates BJ (2006) Nonsystemic bunt Fungi - Tilletia indica and T. horrida: a review of history, systematics, and biology. Annu Rev Phytopathol 44:113-133

Carris LM, Castlebury LA, Huang G, Alderman SC, Luo J et al (2007) Tilletia vankyi, a new species of reticulate-spored bunt fungus with non-conjugating basidiospores infecting species of Festuca and Lolium. Mycol Res 111:1386-1398

Castlebury LA, Carris LM (1999) Tilletia walkeri, a new species on Lolium multiflorun and L. perenne. Mycologia 91:121-131

Castlebury LA, Carris LM, Vánky K (2005) Phylogenetic analysis of Tilletia and allied genera in order Tilletiales (Ustilaginomycetes; Exobasidiomycetidae) based on large subunit nuclear rDNA sequences. Mycologia 97:888-900

Chang Y, Wang S, Sekimoto S, Aerts AL, Choi C et al (2015) Phylogenomic analyses indicate that early fungi evolved digesting cell walls of algal ancestors of land plants. Genome Biol Evol 7:1590-1601

Corrochano LM, Kuo A, Marcet-Houben M, Polaino S, Salamov A et al (2016) Expansion of signal transduction pathways in fungi by extensive genome duplication. Curr Biol 26:1577-1584

Cunfer B, Castlebury LA (1999) Tilletia walkeri on annual ryegrass in wheat fields in the southeastern United States. Plant Dis 83:685-689

Eddy SR (2009) A new generation of homology search tools based on probabilistic inference. In: Morishita S, Lee SY, Sakakibara Y (eds) Genome informatics 2009, proceedings of the 20th international conference. Imperial College Press, Singapore, pp 205-211

Edgar RC (2004) MUSCLE: multiple sequence alignment with high accuracy and high throughput. Nucleic Acids Res 32:1792-1797

Emms DM, Kelly S (2015) OrthoFinder: solving fundamental biases in whole genome comparisons dramatically improves orthogroup inference accuracy. Genome Biol 16:157

Enright A, Van Dongen S, Ouzounis C (2002) An efficient algorithm for large-scale detection of protein families. Nucleic Acids Res 30:1575-1584

Finn RD, Attwood TK, Babbitt PC, Bateman A, Bork P et al (2017) InterPro in 2017beyond protein family and domain annotations. Nucleic Acids Res 45:D190-D199

Floudas D, Binder M, Riley R, Barry K, Blanchette RA et al (2012) The Paleozoic origin of enzymatic lignin decomposition reconstructed from 31 fungal genomes. Science 336:1715-1719

Frederick RD, Snyder KE, Tooley PW, Berthier-Schaad Y, Peterson GL et al (2000) Identification and differentiation of Tilletia indica and I using the polymerase chain reaction. Phytopathology 90:951-960 
Galagan JE, Calvo SE, Borkovich KA, Selker EU, Read ND et al (2003) The genome sequence of the filamentous fungus Neurospora crassa. Nature 422:859-868

Gao L, Yu H, Han W, Gao F, Liu T et al (2014) Development of a SCAR marker for molecular detection and diagnosis of Tilletia controversa Kühn, the causal fungus of wheat dwarf bunt. World J Microbiol Biotechnol 30:3185-3195

Gao Y, Tan MK, Zhu YG (2016) Rapid and specific detection of Tilletia indica using loop-mediated isothermal DNA amplification. Aust Plant Pathol 45:361-367

García-Alcalde F, Okonechnikov K, Carbonell J, Cruz LM, Göz S et al (2012) Qualimap: evaluating next-generation sequencing alignment data. Bioinformatics 28:2678-2679

Geiser E, Ludwig F, Zambanini T, Wierckx N, Blank LM (2016) Draft genome sequences of itaconate-producing ustilaginaceae. Genome Announc 4:e01291-e01216

Gioti A, Nystedt B, Li W, Xu J, Andersson A et al (2013) Genomic insights into the atopic eczema-associated skin commensal yeast Malassezia sympodialis. MBio 4: e00572-e00512

Goffeau A, Barrell BG, Bussey H, Davis R, Dujon B et al (1996) Life with 6000 genes. Science 274:546-567

Goris J, Konstantinidis KT, Klappenbach JA, Coenye T, Vandamme P et al (2007) DNA-DNA hybridization values and their relationship to whole-genome sequence similarities. Int J Syst Evol Microbiol 57:81-91

Grigoriev IV, Nikitin R, Haridas S, Kuo A, Ohm R et al (2014) MycoCosm portal: gearing up for 1000 fungal genomes. Nucleic Acids Res 42:D699-D704

Gurevich A, Saveliev V, Vyahhi N, Tesler G (2013) QUAST: quality assessment tool for genome assemblies. Bioinformatics 29:1072-1075

Gurjar S, Aggarwal R, Jogawat A, Sharma S, Kulshreshtha D et al (2017) Development of real time PCR assay for detection and quantification of teliospores of Tilletia indica in soil. Indian J Exp Biol 55:549-554

Haitjema CH, Gilmore SP, Henske JK, Solomon KV, de Groot R et al (2017) A parts list for fungal cellulosomes revealed by comparative genomics. Nat Microbiol 2:17087

Hall B, DeRego T, Geib S (2014) GAG: the genome annotation generator (version 1.0). Available from http://genomeannotation.github.io/GAG

Heberle H, Meirelles GV, da Silva FR, Telles GP, Minghim R (2015) InteractiVenn: a web-based tool for the analysis of sets through Venn diagrams. BMC Bioinformatics 16:169

Hoff KJ, Lange S, Lomsadze A, Borodovsky M, Stanke M (2016) BRAKER1: unsupervised RNA-Seq-based genome annotation with GeneMark-ET and AUGUSTUS. Bioinformatics 32:767-769

IPPC (2016) ISPM 27 diagnostic protocols for regulated pests. Annex DP4: Tilletia indica Mitra. International Plant Protection Convention, Food and Agriculture Organization of the United Nations, Italy

Jain C, Rodriguez-R LM, Phillippy AM, Konstantinidis KT, Aluru S (2018) High throughput $\mathrm{ANI}$ analysis of $90 \mathrm{~K}$ prokaryotic genomes reveals clear species boundaries. Nature Communications 9: 5114

James TY, Pelin A, Bonen L, Ahrendt S, Sain D et al (2013) Shared signatures of parasitism and phylogenomics unite cryptomycota and microsporidia. Curr Biol 23:1548-1553

Josefsen L, Christiansen SK (2002) PCR as a tool for the early detection and diagnosis of common bunt in wheat, caused by Tilletia tritici. Mycol Res 106: 1287-1292

Kämper J, Kahmann R, Bölker M, Ma L-J, Brefort T et al (2006) Insights from the genome of the biotrophic fungal plant pathogen Ustilago maydis. Nature 444:97-101

Kijpornyongpan T, Mondo SJ, Barry K, Sandor L, Lee J et al (2018) Broad genomic sampling reveals a smut pathogenic ancestry of the fungal clade Ustilaginomycotina. Mol Biol Evol 35:1840-1854

Kim D, Pertea G, Trapnell C, Pimentel H, Kelley R et al (2013) TopHat2: accurate alignment of transcriptomes in the presence of insertions, deletions and gene fusions. Genome Biol 14:R36

Kochanová M, Zouhar M, Prokinová E, Rysanek P (2004) Detection of Tilletia controversa and Tilletia caries in wheat by PCR method. Plant Soil Environ 50:75-77

Konishi M, Hatada Y, Horiuchi J-i (2013) Draft genome sequence of the basidiomycetous yeast-like fungus Pseudozyma hubeiensis SY62, which produces an abundant amount of the biosurfactant mannosylerythritol lipids. Genome Announc 1:e00409-e00413

Kumar A, Mishra P, Maurya R, Mishra AK, Gupta VK et al (2018) Improved draft genome sequence of a monoteliosporic culture of the Karnal bunt (Tilletia indica) pathogen of wheat. Genome Announc 6:e00015-e00018

Kumar A, Pandey V, Singh M, Pandey D, Saharan M et al (2017) Draft genome sequence of Karnal bunt pathogen (Tilletia indica) of wheat provides insights into the pathogenic mechanisms of quarantined fungus. PLoS One 12: e0171323
Kurtz S, Phillippy A, Delcher AL, Smoot M, Shumway M et al (2004) Versatile and open software for comparing large genomes. Genome Biol 5:R12

Langmead B, Salzberg SL (2012) Fast gapped-read alignment with bowtie 2. Nat Methods 9:357-359

Lastovetsky OA, Gaspar ML, Mondo SJ, LaButti KM, Sandor L et al (2016) Lipid metabolic changes in an early divergent fungus govern the establishment of a mutualistic symbiosis with endobacteria. Proc Natl Acad Sci USA 113: 15102-15107

Laurie JD, Ali S, Linning R, Mannhaupt G, Wong P et al (2012) Genome comparison of barley and maize smut fungi reveals targeted loss of RNA silencing components and species-specific presence of transposable elements. Plant Cell 24:1733-1745

Levy L, Castlebury LA, Carris LM, Meyer RJ, Pimentel G (2001) Internal transcribed spacer sequence-based phylogeny and polymerase chain reaction-restriction fragment length polymorphism differentiation of Tilletia walkeri and T. indica. Phytopathology 91:935-940

Liu JH, Gao L, Liu TG, Chen WQ (2009) Development of a sequence-characterized amplified region marker for diagnosis of dwarf bunt of wheat and detection of Tilletia controversa Kuhn. Lett Appl Microbiol 49:235-240

Lorenz S, Guenther M, Grumaz C, Rupp S, Zibek S et al (2014) Genome sequence of the basidiomycetous fungus Pseudozyma aphidis DSM70725, an efficient producer of biosurfactant mannosylerythritol lipids. Genome Announc 2: e00053-e00014

Ma L-J, Ibrahim AS, Skory C, Grabherr MG, Burger G et al (2009) Genomic analysis of the basal lineage fungus Rhizopus oryzae reveals a whole-genome duplication. PLoS Genet 5:e1000549

Matanguihan JB, Murphy KM, Jones SS (2011) Control of common bunt in organic wheat. Plant Dis 95:92-103

McDonald J, Wong E, White G (2000) Differentiation of Tilletia species by rep-PCR genomic fingerprinting. Plant Dis 84:1121-1125

McNeil M, Roberts A, Cockerell V, Mulholland V (2004) Real-time PCR assay for quantification of Tilletia caries contamination of UK wheat seed. Plant Pathol 53:741-750

Mirarab S, Warnow T (2015) ASTRAL-II: coalescent-based species tree estimation with many hundreds of taxa and thousands of genes. Bioinformatics 31:i44-i52

Mondo SJ, Dannebaum RO, Kuo RC, Louie KB, Bewick AJ et al (2017) Widespread adenine N6-methylation of active genes in fungi. Nat Genet 49:964-968

Morin E, Kohler A, Baker AR, Foulongne-Oriol M, Lombard V et al (2012) Genome sequence of the button mushroom Agaricus bisporus reveals mechanisms governing adaptation to a humic-rich ecological niche. Proc Natl Acad Sci USA 109:17501-17506

Nikolenko SI, Korobeynikov Al, Alekseyev MA (2013) BayesHammer: Bayesian clustering for error correction in single-cell sequencing. BMC Genomics 14(Suppl 1):S7

Nordberg H, Cantor M, Dusheyko S, Hua S, Poliakov A et al (2013) The genome portal of the Department of Energy Joint Genome Institute: 2014 updates. Nucleic Acids Res 42(D1):D26-D31

OEPP/EPPO (2016) PM 3/78 (1) consignment inspection of seed and grain of cereals. Bull OEPP/EPPO Bull 46:49-57

Petre B, Kamoun S (2014) How do filamentous pathogens deliver effector proteins into plant cells. PLoS Biol 12:e1001801

Pimentel G, Carris LM, Levy L, Meyer RJ (1998) Genetic variability among isolates of Tilletia barclayana, T. indica and allied species. Mycologia 90:1017-1027

Pimentel G, Carris LM, Peever TL (2000) Characterization of interspecific hybrids between Tilletia controversa and T. bromi. Mycologia 92:411-420

Richter M, Rossello-Mora R (2009) Shifting the genomic gold standard for the prokaryotic species definition. Proc Natl Acad Sci USA 106:19126-19131

Russell BW, Mills D (1994) Morphological, physiological, and genetic evidence in support of a conspecific status for Tilletia caries, T. controversa, and T. foetida. Phytopathology 84:576-582

Samson RA, Houbraken J, Thrane U, Frisvad JC, Andersen B (2010) Food and Indoor Fungi. CBS Laboratory Manual Series 2. CBS-KNAW Fungal Biodiversity Centre, Utrecht

Schirawski J, Mannhaupt G, Münch K, Brefort T, Schipper K et al (2010) Pathogenicity determinants in smut fungi revealed by genome comparison. Science 330:1546-1548

Sharma P, Tiwari R, Saharan M, Sharma I, Kumar J et al (2016) Draft genome sequence of two monosporidial lines of the Karnal bunt fungus Tilletia indica Mitra (PSWKBGH-1 and PSWKBGH-2). Genome Announc 4:e00928-e00916 
Shi Y, Loomis P, Christian D, Carris L, Leung H (1996) Analysis of the genetic relationships among the wheat bunt fungi using RAPD and ribosomal DNA markers. Phytopathology 86:311-318

Simão FA, Waterhouse RM, loannidis P, Kriventseva EV, Zdobnov EM (2015) BUSCO: assessing genome assembly and annotation completeness with single-copy orthologs. Bioinformatics 31:3210-3212

Spatafora JW, Chang Y, Benny GL, Lazarus K, Smith ME et al (2016) A phylumlevel phylogenetic classification of zygomycete fungi based on genomescale data. Mycologia 108:1028-1046

Sperschneider J, Dodds PN, Gardiner DM, Singh KB, Taylor JM (2018) Improved prediction of fungal effector proteins from secretomes with EffectorP 2.0. Mol Plant Pathol 19:2094-2110

Stamatakis A (2014) RAxML version 8: a tool for phylogenetic analysis and postanalysis of large phylogenies. Bioinformatics 30:1312-1313

Tan M-K, Ghalayini A, Sharma I, Yi J, Shivas R et al (2009) A one-tube fluorescent assay for the quarantine detection and identification of Tilletia indica and other grass bunts in wheat. Aust Plant Pathol 38:101-109

Tan M-K, Murray GM (2006) A molecular protocol using quenched FRET probes for the quarantine surveillance of Tilletia indica, the causal agent of Karnal bunt of wheat. Mycol Res 110:203-210

Tan M-K, Raman H, Chambers G, Sharma I, Chen Z et al (2016) Characterization of SNP and structural variations in the mitochondrial genomes of Tilletia indica and its closely related species formed basis for a simple diagnostic assay. PLoS One 11:e0166086

Taniguti LM, Schaker PD, Benevenuto J, Peters LP, Carvalho G et al (2015) Complete genome sequence of Sporisorium scitamineum and biotrophic interaction transcriptome with sugarcane. PLoS One 10:e0129318

Thirumalaisamy P, Singh D, Aggrawal R, Gogoi R, Gupta P et al (2011) Development of species-specific primers for detection of Karnal bunt pathogen of wheat. Indian Phytopathol 64:164-172

Tisserant E, Malbreil M, Kuo A, Kohler A, Symeonidi A et al (2013) Genome of an arbuscular mycorrhizal fungus provides insight into the oldest plant symbiosis. Proc Natl Acad Sci USA 110:20117-20122

Toome M, Kuo A, Henrissat B, Lipzen A, Tritt A et al (2014a) Draft genome sequence of a rare smut relative, Tilletiaria anomala UBC 951. Genome Announc 2:e00539-e00514

Toome M, Ohm RA, Riley RW, James TY, Lazarus KL et al (2014b) Genome sequencing provides insight into the reproductive biology, nutritional mode and ploidy of the fern pathogen Mixia osmundae. New Phytol 202:554-564

Trail F, Mills D (1990) Growth of haploid Tilletia strains in planta and genetic analysis of a cross of Tilletia caries X T. controversa. Phytopathology 80:367-370

Treangen TJ, Ondov BD, Koren S, Phillippy AM (2014) The harvest suite for rapid core-genome alignment and visualization of thousands of intraspecific microbial genomes. Genome Biol 15:524

Trione EJ (1964) Isolation and in vitro culture of wheta bunt fungi, Tilletia caries and Tilletia controversa. Phytopathology 54:592-596

Uehling J, Gryganskyi A, Hameed K, Tschaplinski T, Misztal P et al (2017) Comparative genomics of Mortierella elongata and its bacterial endosymbiont Mycoavidus cysteinexigens. Environ Microbiol 19:2964-2983

Wang N, Ai P, Tang Y, Zhang J, Dai X et al (2015) Draft genome sequence of the rice kernel smut Tilletia horrida strain QB-1. Genome Announc 3:e00621-e00615

Wilcoxson RD, Saari EE (1996) Bunt and Smut diseases of wheat: concepts and methods of disease management, vol 4. CIMMYT, Mexico

Wood V, Gwilliam R, Rajandream M-A, Lyne M, Lyne R et al (2002) The genome sequence of Schizosaccharomyces pombe. Nature 415:871-880

Xu J, Saunders CW, Hu P, Grant RA, Boekhout T et al (2007) Dandruff-associated Malassezia genomes reveal convergent and divergent virulence traits shared with plant and human fungal pathogens. Proc Natl Acad Sci USA 104:18730-18735

Zajc J, Liu Y, Dai W, Yang Z, Hu J et al (2013) Genome and transcriptome sequencing of the halophilic fungus Wallemia ichthyophaga: haloadaptations present and absent. BMC Genomics 14:617

Zouhar M, Mazáková J, Prokinová E, Vánová M, Ryšánek P (2010) Quantification of Tilletia caries and Tilletia controversa mycelium in wheat apical meristem by real-time PCR. Plant Protect Sci 46:107-115

Župunski V, Jevtić R, Ignjatović-Micić D, Stanković S, Lević J et al (2012) Incidence of Tilletia species in non-processed seed of Triticum aestivum in Vojvodina. Serbia Seed Sci Technol 40:320-332

\section{Publisher's Note}

Springer Nature remains neutral with regard to jurisdictional claims in published maps and institutional affiliations.

Ready to submit your research? Choose BMC and benefit from:

- fast, convenient online submission

- thorough peer review by experienced researchers in your field

- rapid publication on acceptance

- support for research data, including large and complex data types

- gold Open Access which fosters wider collaboration and increased citations

- maximum visibility for your research: over $100 \mathrm{M}$ website views per year

At BMC, research is always in progress.

Learn more biomedcentral.com/submissions 